\title{
11. Opportunities for National Biography Online: The Oxford Dictionary of National Biography, 2005-2012
}

\author{
Philip Carter
}

\begin{abstract}
Anniversaries, like that to mark the Australian Dictionary of Biography's recent half-century, are principally times for looking back and reflecting on what has been done. But they can also be opportunities for assessing current situations and thinking about the future: what could be done, and what might be possible at the start of the next half-century. For most of the $A D B$ 's first 50 years the sole medium for publishing Australian lives, and those of other national biographies, was print, either as sequential chronological volumes - as favoured by the $A D B$ and the Dictionary of Canadian Biography $(D C B)$ and the Dictionary of New Zealand Biography $(D N Z B)$ - or as complete series, as with the American National Biography $(A N B)$ and the Oxford Dictionary of National Biography $(O D N B)$, which appeared in 1999 and 2004 respectively.
\end{abstract}

The last two titles were also notable for their simultaneous online editions, marking an important development in how national biographies are made available and may be used. By the time the $A D B$ went online in 2006, it joined the $A N B, D C B, O D N B$ and $D N Z B$ (and has itself since been joined by digital versions of the dictionaries of Swedish, Welsh, Ulster and most recently Irish national biography), as well as a range of specialist titles including dictionaries of Scottish architects, labour biography, the New Grove dictionaries of art and music, and the United Kingdom's History of Parliament. As a solely print publication, the 25-volume Diccionario Biográfico Español (2011) is the exception that proves the rule.

In response to online publishing's ascendency, practices and expectations are being transformed as publishers, researchers and readers come to appreciate the close fit between that eminently traditional genre, biographical reference, and the contemporary medium of the Internet. The degree of this transformation is worthy of note. As recently as 2004-05 there was, among editors and publishers of the $O D N B$, a sense that its print and online versions were equal partners that most readers would use interchangeably. Now, as we approach the tenth anniversary of the $O D N B$ 's publication, what is striking is the extent to which the online edition has become the dominant and preferred form for reference, research and also reading. An anniversary like the $A D B^{\prime}$ s therefore 
allows us to appreciate how the recent past, the present and most certainly the future of national biography lie online. But the $A D B$ anniversary also prompts consideration of several further issues. What, for example, does the ascendancy of online reference mean for how national biographies are being (and could be) compiled? How might the online environment shape editors' work as custodians of their respective national histories? To what extent are researchers willing to treat online dictionaries not just as 'super-accessible print' but as new resources in which the ability to make connections between people shifts perspectives from biography to history; from, in effect, discrete biographies of those who shaped a nation to a nation's history told through the lives of its people?

This chapter considers these topics by looking principally at the recent history of the $O D N B$ online, though where possible also with reference to the $A D B$ and to other national biographies. After setting the respective dictionaries in context, the chapter considers the $O D N B$ 's experience - aims, challenges and, above all, opportunities - through several stages: its inception as a continuous online publication; the extension and interpretation of biographical content; the work to preserve and improve prompted by other online resources; and attempts to use digital publicity and social media to promote the dictionary as a national resource and institution. The chapter's conclusion returns to challenges and opportunities - witnessed and perhaps future - with particular reference to research possibilities within and between national biographies, a subject of shared interest for the $O D N B$ and the $A D B$.

\section{$O D N B$ and $A D B$ in context}

In early 2005 the $O D N B$ 's publisher, Oxford University Press, began a program of three annual updates in which new biographies and other forms of content (along with revisions to existing entries) were added online in January, May and September of each year. By early 2013 the ODNB had published 25 such updates, which have extended its coverage (which stood at 55113 people in 2004) by a further 3432 men and women, active between the first and twentyfirst centuries, together with 504 'reference articles' designed in various ways to place individuals in historical context. Continuation, extension and upkeep are not unique to the ODNB. Since 2005 the $D N Z B$ online has been part of the larger, interpretative Encyclopaedia of New Zealand site (<http:// TeAra.govt.nz $>$ ); in the following year, the $A D B$ online began a program of corrections and amendments, while from 2000 the $A N B$ has regularly revised and added to its coverage (1348 new lives in 32 sets by late 2012). The last is a model followed by the $D C B$, to which a small selection of biographies has been published ahead of the appropriate print volume, and by the new Dictionary of Irish Biography, with a first update of 36 biographies in November 2010, 
and a further 153 lives in four subsequent updates to 2012. Relative to the $O D N B$, however, these currently remain limited exercises. What distinguishes the $O D N B$ are the extent, complexity and ambition of its online edition, evident both in the amount of biographical and reference content published and in the attention given to its promotion as an accessible, national resource of relevance to multiple readerships.

The attention paid to the $O D N B$ 's development as a national record derives from particular circumstances, reminding us that, while national biographies may have shared aims and approaches, their forms reflect political, cultural and commercial contingencies. The degree to which national circumstances, and even character, might shape the creation and continuation of such works is an interesting question worthy of further consideration. Even a cursory comparison of the historical and cultural contexts in which the ODNB and $A D B$ have been, and continue to be, compiled suggests an influence that is not insignificant. How, for example, does a historically rich, predominantly London-centric society like Britain's create, view and look after its national figures compared with a younger, federal Australia with what (at least to an outsider) appears a more explicit interest in its national story $?^{1}$ One implication is that since 2005 the $O D N B$ online has existed, and as a subscription service must thrive, in a relatively more competitive cultural environment in which the telling of national history is variously undertaken by galleries, museums, archives, public broadcasters and a host of free, 'open-web' resources.

Comparisons between the $O D N B$ and the $A D B$ point to further differences, most notably that the Oxford project is at a different phase in its academic and publishing cycle, with important consequences for what is required and possible for its respective digital editions. Thus, with a full $\mathrm{A}-\mathrm{Z}$ sequence already published, editors at the $O D N B$ are able to combine work to extend the dictionary's coverage with that of 'curating' the 55000 lives already in place. That we now see ourselves as curators as well as academic editors is a significant transition, and one directly attributable to an online format in which a traditional, alphabetical 'national biography' has become a digital 'national collection'. The implications of this changing perception are wide ranging, intellectually stimulating and as yet little considered. Released from the presentational strictures of print reference, it is possible online to select, study, connect and present historical individuals or groups of people in new ways. Indeed, such is the importance of this idea that, as this chapter suggests,

1 For an early commentary on the influence of 'national preoccupations', with a specific focus on the $A D B$, see James Walter, 'Seven Questions about National Biography', in Iain McCalman, with Jodi Parvey and Misty Cork (eds), National Biographies and National Identity (Canberra: Humanities Research Centre, 1996), pp. 22-6. 
it is as meaningful to understand today's $O D N B$ with reference to museums or galleries - to speak of acquisition and interpretation, preservation, curation and outreach — as it is to traditional book publishing.

These specific national contexts and publishing histories inevitably make for distinctive forms of Australian and British biography. Equally the growing prominence of online formats in reference publishing, and the appreciation of editors in Oxford and Canberra as to its importance, also reminds us of the connections between our projects and those of other national biographies. Though online reference is now ubiquitous, the $O D N B$ and $A D B$ are examples of what is still quite a rare creature: an academically rigorous, trusted and sustained resource that has transferred or is in the process of transferring to a wholly online environment committed to further development. The particular focus on the $O D N B$, as here, seems warranted given the distance it has come since 2005 as a pioneer of this genre - serving to highlight the changing working methods, requirements and perceptions of national biography derived from being online. Some of these experiences remain particular to a project in a specific intellectual and cultural climate, but others do suggest shared opportunities for national biography.

\section{Online from 2005: Three decisions}

Publication of the $O D N B$ in 2004 brought to a close a 12-year research and publishing project of the University of Oxford and Oxford University Press. The edition comprised newly written, or substantially revised, versions of the 38 607 biographies that had made up the 'first' $D N B$, consisting of Leslie Stephen and Sidney Lee's 'Victorian edition' - that is, 63 volumes (1885-1900) and its retrospective supplement (1901), together with the decennial and quinquennial volumes that mapped the twentieth century (published between 1912 and 1996), and a further 'missing persons' volume in 1993. To this set, the 2004 edition added biographies of a further 16315 men and women active (with a handful of exceptions) between the first and the late-twentieth centuries and deceased on or before 31 December 2000.

Well before publication of the complete series of 55113 lives, attention turned to the dictionary's future with a particular focus on its online presence after 2004. Here several options were available to a title that had been published as a complete sequence in then identical print and online editions. One possibility was to keep the content stable, at least for a few years, which was perhaps not unreasonable given the dictionary's scale and the research opportunities awaiting its readers. That this was not considered, even then, owed much to the prevailing intellectual case for continuing to extend a collection whose 
50000 articles (in which the 55113 lives appeared) had always been regarded as a sensible marker, not the sum total, of British history. Seeking to develop the dictionary's content from publication also showed an appreciation that successful online reference, then in its infancy, both could and should 'add value' relative to print. Rejecting stasis in favour of 'organicism' now required decisions concerning the definition of 'value': what was to be added and why? ${ }^{2}$

The first decision was to ensure the dictionary's chronological progressionthat is, the addition of people who had died in or after 2001. This made lexicographical sense, being readily interpretable and innovative; then, and now, no other national biography systematically covers the 'recently deceased' and with it late-twentieth and twenty-first century history. Since 2005 it has led to the publication of one annual update (released each January), which adds about 220 biographies of people who died in a single calendar year. Beginning in January 2005 with those who died in 2001, the current sequence involving just less than 1950 individuals, now includes (with the January 2013 update) men and women who died on or before 31 December 2009.

Having committed to extending modern content, attention turned to editors' responsibilities for the dictionary as a whole. The outcome saw January updates combined with two further annual releases (published each May and September) that would include people, from all historical periods, who were either known omissions in 2004 or recently identified subjects arising from new research or reviews of existing coverage. This second decision was perhaps the most important for the $O D N B^{\prime}$ s future course. It meant that the continuation project would not just be one of chronological extension, as practised in print by several ongoing biographies, including the $A D B$; it would also involve improving the work as a whole, a process that has seen the addition (by May 2013) of 1609 men and women covering 1000 years of British history worldwide.

At the same time, a commitment to pre-2000 coverage was intended as more than filling known 'gaps'. Rather, new additions across the dictionary should also serve as a means for editors to draw attention to, and make connections between, existing biographies. This was important given the scale of the dictionary, in which valuable content might otherwise remain hidden, and because of readers' understandable preference for searching person-by-person rather than (as online now allowed) by historical topic or theme. Seeing new and existing content as interconnected also made clear the need for, and value of, maintaining the quality of individual entries throughout the dictionary. In

2 On the notion of the $O D N B$ online as 'organic', see Lawrence Goldman, 'No Smoking Dons. The $O D N B$ and the New Structures of Knowledge', Times Literary Supplement (4 February 2005), <http://www.the-tls. co.uk/tls/archives/> 
The ADB's Story

response came a third and final decision, notable for confirming the dictionary's future organicism, to extend the remit of online updates to include also reviews of the complete text, providing corrections, additions and revisions as required.

\section{Extending $O D N B$ online: New people}

Since 2005 two selection processes have been devised for identifying new candidates for inclusion in the dictionary. In the first, for updates covering people who died after 2001, the procedure has similarities to that for recent, and forthcoming, volumes of the $A D B$ - that is, possible subjects (drawn principally from searches of national and international obituary records) are reviewed by external experts until a final listing of approximately 200 people is chosen as the dictionary's coverage of a single calendar year. Where the process between the $O D N B$ and the $A D B$ differs is in the nature of selection and decision making. In contrast with the $A D B$ 's State-based working parties, for whom the principal criterion is geographic, Oxford's external advisers are thematic subject specialists (450 in more than 40 subject panels, from archaeology to zoology) who are asked to assess the relative contribution of individuals in their field and to make nominations for possible inclusion. Thereafter the final decision on who to include is made by the $O D N B^{\prime}$ s general editor and the section editor responsible for coverage of recent subjects.

For subjects from earlier historical periods, a second, wholly thematic procedure has been developed, with sets of interconnected biographies linked by profession, place or research area, and often spanning several centuries in their consideration of a historical topic. Here a decision to include a specific set of biographies may have one of several origins. In some areas known imbalances in coverage have prompted long-term research projects to add new biographies in updates over several years; of these, examples include improved coverage of the later empire and early Commonwealth, and the inclusion of 100 early English bishops to provide a complete, and unique, biographical register of the pre-Reformation episcopacy.

Other selections have addressed developments in the historical understanding of specific professions (for example, British domestic and imperial policing, a subject that, until recently, lagged behind that of criminality); of popular activities and recreations, including motoring and horticulture; and of emerging areas of historical study, such as domestic service or childhood. Several additional selections have provided historical interpretations of current events, most notably, British sporting pioneers for the 2012 Olympic Games. Further sets are chosen with reference to place, be this people active beyond the 
former empire (another growing area of research prompting extended coverage of Britons in Latin America, Russia and Japan), the nation-states of the United Kingdom, or prominent cities and regions within England.

This thematic approach to new content serves editors, and readers, well in several ways. Above all, it allows us to add to the dictionary in a systematic and interpretable manner, akin to a special issue of an academic journal on a particular topic. In doing so editors seek to carry over some of the established and readily intelligible structures of print publishing to an online format where, now freed from chronology or alphabetical sequence, there is a risk of new material being added in a random, piecemeal manner. In-house, the thematic approach allows editors to accumulate suggestions from scholars and readers, often gathered over several years, and then to have external specialists assess candidates on their merits relative to others in a similar field, allowing for a more systematic application of the dictionary's inclusion criterion of 'noteworthiness'. In doing so, sets of new biographies in effect become short-term research projects in which editors immerse themselves in a particular subject (the history of policing or domestic service, and so on), enabling them better to identify and address limitations in the dictionary's coverage.

To think thematically is also to think lexicographically - that is, to consider the dictionary's content, presentation, usefulness and readership in the round. Extending coverage since 2005 has encouraged greater editorial focus on the interests and expectations of readerships that now go well beyond the academic specialists who oversaw additions to the 2004 edition. Here in-house editors are well placed to guide the dictionary's development, being both familiar with the existing coverage of subjects and aware of historical categories that were underplayed or not addressed prior to 2004. To this editors also bring an appreciation of the breadth of new content needed to maintain the dictionary as a national resource, within and beyond the academy.

The implications of this approach may be seen in the recent set of British policemen and women active between the early nineteenth and late-twentieth centuries. For the $O D N B$ - as scholarly reference work, public resource and national commentary - such selections must go beyond an 'institutional' survey to include people connected to well-known events or innovations about which readers may wish to learn more through biography. To offer several examples from the series: the pioneer of fingerprinting, Francis Cherrill (1892-1964); Walter Dew (1863-1947), the detective who crossed the Atlantic to arrest Dr Crippen in 1910; or WPC Yvonne Fletcher (1958-84) whose murder outside the Libyan Embassy led to the breakdown in relations between London and Tripoli and to new forms of public commemoration for officers killed on duty. When they do appear, chief constables are included not for their rank but for their activities - as in the case of Mowbray Lees Sant (1863-1943), who, infuriated by 
'speeding' motorists, introduced the country's (and most probably the world's) first speed traps three months before the death of Queen Victoria; or Eric St Johnston (1911-86), who, in promoting the move from policing on foot to motorised patrols, oversaw a profound change to the modern service.

Up to a point, this recent approach to content echoes one long practised in the $A D B$. In 1998 the $A D B$ 's editor, John Ritchie, gave a talk in Oxford in which he explained the policy of including 'representative' lives that encapsulated a social movement or new professional category, his example being Aileen Keldie, an airline stewardess killed in a plane crash between Sydney and Canberra in November 1961. At the time there was agreement that, here, the two dictionaries differed, with the $O D N B$ requiring that a person be, if not exceptional, then at least historically noteworthy relative to others and identifiable for having left a mark on national life broadly defined. This principle still applies. And yet, in response to the inherited structures of the 2004 edition and in mind of modern readerships, the recent interest in thinking and commissioning lexicographically does now mean a greater focus on lives that represent different interests or offer a balanced representation of subject areas, such as policing.

So, too, with geographical surveys of content: there has always been an element of this. For the 2004 edition, Oxford editors were commissioned with specific reference to Scotland, Wales and Ireland and in relation to people from or influential in former colonies. In Britain London dominates, unlike in Australia where the federal system foregrounds and privileges the States and Territories. Metropolitan dominance, coupled with the absence of pronounced expressions of English regionalism, meant that there was less historical motivation, or political encouragement, to consider coverage in terms of the north-east, Cornwall, East Anglia and so on. Since 2005, however, regionalism has emerged as an increasingly useful category for Oxford editors to assess and extend coverage. Derived directly from the dictionary's online availability, a principal reason has been the growing numbers who access the ODNB through the UK public library network. This follows an agreement, initially with English library authorities in 2006, and subsequently extended to cover Northern Ireland and most of Wales and Scotland, by which the $O D N B$ is provided as a free online resource, with most libraries now offering 'remote access', which allows members to login via a home computer (or from anywhere), at anytime. This agreement has been of considerable benefit, enabling us to promote the online edition as a genuinely national and public resource. Encouraging the dictionary's use in libraries in turn prompts closer attention to the coverage of regional histories and 'local figures' deserving of national recognition. The outcome has seen the inclusion both of people and of groups: notable individuals, among them Jack Crawford (1775-1831), the sailor who 'nailed the colours to the mast', recently 
commemorated with a statue in his native Sunderland; and thematic sets of biographies, including of brewers and school-founders, highlighting national professions and institutions with which readers also have close regional ties. ${ }^{3}$

\section{Connecting and interpreting: Biography to history}

Though a key feature since 2005 has been the rapid take-up of the ODNB online, questions remain as to how the dictionary is being used. The challenge faced by editors and publishers is to persuade readers, even those comfortable with online research, that resources like the $A D B$ and $O D N B$ online offer more than the print edition on screen. So, while the growth of online use has been very welcome, it is also the case that it remains largely conservative: more than 90 per cent of entry points to <oxforddnb.com $>$ are by personal name, as one would consult the print volumes. This means that only a small proportion of readers is using the online edition to its full potential as a research tool that not only records 'what is already known', but also offers opportunities for new discoveries in ways unachievable in print. This has surprised Oxford editors, not least because cross-subject searching, and the ability to create new sets of biographical data, is one aspect of functionality offered (to varying degrees) by the majority of national biographies online, but not available in popular alternatives such as Wikipedia.

The $O D N B$ 's electronic index is capable of searching for people by combinations of name, date, place, profession, gender and religious affiliation, as well as by wealth at death, archive holdings, and portrait records. Thus it is possible, in seconds, to bring together 20 female political activists resident in Manchester in the 1890s; 15 natives of Melbourne living in London during the Blitz; 200 people in the $O D N B$ with a statue, bust or tomb in Westminster Abbey; or the six women writers with papers held by the National Library of Australia. Any connections between Manchester's late-Victorian activists may be tenuousbut, then again, perhaps not. And for some researchers, the ODNB online has offered routes to new research. ${ }^{4}$ Similarly, in university teaching, related entries (for example, suffrage campaigners) are being studied prosopographically, while

\footnotetext{
3 See Mark Curthoys, 'Recent Additions to the Oxford DNB: Local Lives in National Biography', Local Historian, 40, no. 4 (2010), pp. 324-8.

4 For example, I. C. McManus ('The Wealth of Distinguished Doctors: Retrospective Survey', British Medical Journal, 331, no. 7531 [2005], p. 1520) compares wealth-at-death records within a profession. Inhouse surveys include Philip Carter, 'Life on the Square: The Oxford DNB in WC2', Trafalgar Chronicle, 18 (2008), pp. 264-71, which intersects people and place, and a forthcoming article on the social origins of the pre-Reformation episcopacy following completion of the $O D N B^{\prime}$ s listing of church leaders in spring 2011. These examples aside, studies of interconnectivity remain noticeably rare, with most surveys of sets of lives focusing on coverage, from the perspective of professions, the 'four kingdoms' or the nation at large. James
} 
comparisons between the DNB's Victorian and late twentieth-century editions feature in courses on historiography and life writing. ${ }^{5}$ These initiatives are welcome but we would also like academics, teachers and students to make more of the $O D N B$ online as a starting point for research, not just as a means of checking or confirming. This is where two additional forms of online contentthe $O D N B$ 's 'reference lists' and 'reference groups' - play a role: they serve as editors' attempts to nudge readers towards treating the dictionary as a historical resource, capable of charting the connections and exchanges between people who are otherwise covered singly in the main text. It might initially seem odd to associate Donne's 'No man is an island, entire of it self' with biographical reference and, maybe so in its alphabeticised, individuated print format. But online it is a sensible expectation and typically a discoverable reality. ${ }^{6}$

In showing how and where historical connections may be made, the $O D N B$ and $A D B$ currently follow different paths. We both, however, appreciate the potential for making links between people: with projects such as Obituaries Australia, editors at the ANU's National Centre of Biography are creating opportunities to establish hitherto unknown connections from, in effect, the 'bottom up'. These, moreover, are connections that go well beyond what is possible via the existing metadata of the $A D B$ or the $O D N B$ - for example, by bringing people together with reference to places of shared activity other than educational institution or residence, or by tracing sets of interrelated people as they move through different stages of life, from school to university to army service, and so on.

In contrast, the $O D N B$ pursues a more 'top-down' approach with its list and groups - that is, identifying pre-existing structures (be they public offices held consequentially or social networks in which membership was shared contemporaneously) and then highlighting connections between incumbents or members. Since 2005 Oxford editors have compiled and published 150 lists of office-holders. These serve several purposes of which the most obvious is 'quick reference', something that is available in print but which in the $O D N B$ is more accessible and offers links to relevant biographies for further reading. A

Raven's review, while noting that the $O D N B$ 's search facilities alter 'fundamentally the definition and role of the collective biographical dictionary', focuses principally on content: James Raven, 'The Oxford Dictionary of National Biography: Dictionary or Encyclopaedia?', Historical Journal, 50 (2007), pp. 991-1006.

5 For example, Alex Danchev [University of Nottingham], 'The Power of Two', Times Higher Education Supplement (18 September 2008); and 'Lecturers Using the Oxford DNB', <www.oup.com/oxforddnb/info/ learning/uni/usage/> 'Learning Resources' offering ideas for classroom and seminar use have also been developed for the online edition: <www.oup.com/oxforddnb/info/learning/>

6 Despite recent statements on the usefulness of biography - for example, Nick Salvatore, 'Biography and Social History: An Intimate Relationship', Labour History, 87 (2004), pp. 187-92; and 'AHR Roundtable: Historians and Biography', American Historical Review, 114, no. 3 (2009), pp. 573-661 - little has been said about the research potential of national biographies online. An exception is Barbara Caine's discussion of national biography in the context of collected biography: Biography and History (Basingstoke, UK: Palgrave Macmillan, 2010), pp. 59-61. 
second purpose is therefore to provide thousands of new routes into the main dictionary, so offering alternatives to 'name' search where an original inquiry starts with a known person.

With lists, the focus shifts from people to events. Starting with an interest in, say, those involved in the Crimean War, a reader may quickly identify the secretary (or, as here, secretaries) of state for war or, indeed, others round the cabinet table in 1856, so creating profiles of formal networks at points in time. In addition, certain reference lists provide alternative forms of digital indexing that allow historical figures to be identified by criteria that could not be, or were not, tagged in the compilation of the dictionary's metadata. Among this category of lists, and continuing the Crimean theme, are 'Victoria Cross holders in the $O D N B^{\prime}$ (unlike the $A D B$, not all British recipients have entries in the Oxford Dictionary), who otherwise could not be brought together for further study. Similar lists/indexes include the dictionary's 100 Nobel laureates, 80 Oscar recipients, and its collection of saints and subjects of beatification (470 including, from 2010, Mary MacKillop and Cardinal John Henry Newman).

The $O D N B$ 's second approach to historical connections is 400 group biographies, which, on completion, will chart British associational life (its clubs, coteries, gangs, brother and sisterhoods), from the Magna Carta barons and Gunpowder plotters to the discoverers of penicillin and the Angry Young Men. Unlike lists of office-holders that exist elsewhere, there is no equivalent in print or online of the groups project for which 300 essays (each roughly 2500 words long) were in place by 2012. With their ability to connect and link to members' biographies, group articles are particularly well suited to an online environment. Though a recent creation, they are, however, not a new idea, having been proposed in the 1990s by the $O D N B^{\prime}$ s founding editor, Colin Matthew, who foresaw networks as a requirement of modern national biography written and read by scholars now fully attuned to the collective means of historical change. ${ }^{7}$

Editors seek to achieve several things with groups. As with a person's standalone biography, we aim to offer concise, informative accounts of the coteries, circles and sects that readers might encounter either in an ODNB article or in secondary literature and wonder, quite rightly: who or what were the Metaphysical poets, Bluestockings and Lunar Society, or, from overseas, the Founding Fathers, First Fleeters, Scottish Martyrs or Canterbury Association? Several of these will likely be examined from alternative perspectives when the $A D B$ begins its own program of online groups, to which no doubt will be added other, wholly Australian networks such as the Heidelberg School, the Seven Dwarfs, Angry Penguins and perhaps even the Kelly Gang.

7 H. C. G. Matthew, Leslie Stephen and the New DNB (Cambridge: Cambridge University Press, 1995), pp. $26-7$. 


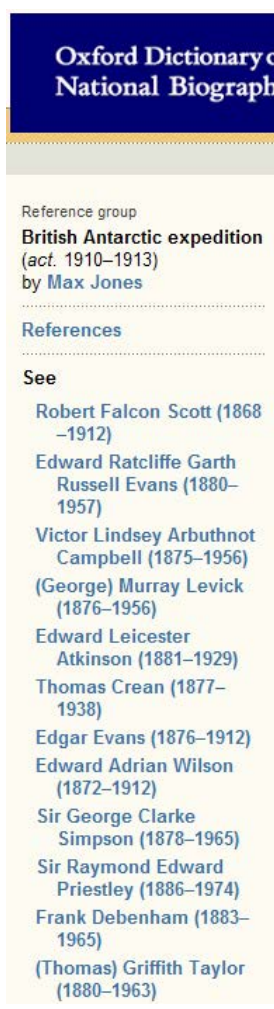

\section{The ODNB 'reference group' charting members of Captain Robert Scott's Antarctic expedition, 1910-13}

A key issue faced by Oxford editors when devising their own interpretative groups was definition: what is a network, and how best to distinguish associations of sufficient coherence from those too disparate or ahistorical to merit study? In response, specific requirements are set. Groups must be historically defined with a beginning and an end point, and they require an identifiable membership, even if participants did not see themselves as forming a group, as in the case of the 15 'Guilty Men' who were externally labelled for their pro-appeasement stance in the late 1930s. ${ }^{8}$ Consequently, open-ended or retrospective affiliations such as 'Scottish Enlightenment thinkers' do not have a place while members of the Edinburgh Select Society (act. 1754-76) or the Aberdonian Wise Club (act. 1758-73) are included. In addition, ODNB group essays must, wherever possible, provide readers with full membership lists (regardless of whether these participants have entries in the main dictionary), as well as information on why and how they came together, what they did, their legacy and, where known, how associations changed individual careers or lives.

8 Cato [Michael Foot, Peter Howard and Frank Owen], Guilty Men new edn (London: Penguin, 1998). D. J. Dutton, 'Guilty Men' (act. 1940), <www.oxforddnb.com/public/themes/70/70401.html> 
By being comprehensive it is possible to establish first-time connections between individuals who were members of the same group, as well as to identify history's 'serial joiners' who were members of numerous networks. More broadly, we can consider how concepts of civil association have changed over time; how, why and where particular types of circles formed; and how the historical memory of particular networks has been shaped by subsequent events. Lastly, from the lexicographer's perspective, groups (and lists) provide an effective means of systematically reviewing and combing existing content for notable 'missing people' who are, in turn, added to the dictionary in annual updates.

\section{Conserving the collection}

If national biographies online have implications for how we encounter, study and teach aspects of the past, it is also the case that other digital resources are radically changing what is possible, and indeed expected, in works of record like the $O D N B$ or $A D B$. Several factors make this particularly so for the $O D N B$, which benefits from the United Kingdom's relatively limited privacy laws (copies of birth, marriage and death certificates, for example, are readily available to 2005) and, more recently, from a boom in the provision of such documents driven by a growing interest in family history.

In its first incarnation, 1993-2004, the $O D N B$ was in large part compiled with core biographical sources that had barely altered since the days of Stephen and Lee. But in its second, wholly online incarnation (2005-) the opportunities for research are hugely expanded, and continue to be so at a remarkable rate. Of these, the most significant include: national census returns for eight surveys held between 1841 and 1911; searchable indexes of civil registration in England and Wales (births, marriages and deaths from 1838); an ever-growing selection of English parish registers (including those in the London Metropolitan Archive); Scottish parish registers from about 1500 and civil registration registers from 1855; English and Welsh probate registers (1861-1966), providing details of residence and death as well as wealth; and wills dating from the sixteenth century via The National Archives, Kew, and Scotland's People web site, a partnership of the General Register Office for Scotland and the National Archives of Scotland. Many of these resources allow documents to be downloaded directly, giving quick access to a record that, prior to digitised searching, may have been impossible to locate.

Beyond these core resources, the National Archives and commercial sites like Ancestry offer numerous other records of biographical relevance, from early modern seals and passenger shipping lists to military service records and telephone directories, providing details of residence for the years after the last 
public census. Meanwhile, the British Library's 'British newspapers, 1800-1900' service provides nearly 50 national and regional papers, to be used alongside existing resources such as the Times digital archive (1785-2006).

Finally, the recent launch of open web sites such as the 'Clergy of the Church of England database 1540-1835', with listings of more than 100000 clerics; the 'Old Bailey online, 1674-1913', providing details of nearly 200000 criminal trials and the life stories of 2500 victims of execution; and 'London lives, 16901800', with 240000 manuscripts naming nearly 3.5 million Londoners, provide wonderfully rich resources for investigating early modern social trends through biography.

A principal benefit of resources like these is the opportunity to add information that in 2004 was either unknown (and undocumented in secondary sources) or could not be located from searches of printed catalogues. This applies most obviously to core biographical data that are now more easily available via digitised registration catalogues or census records, places and dates of birth, marriage and death, as well as details of subjects' parents, spouses and immediate family. In 2004, terms such as 'details of which are unknown' or 'remains elusive' appeared at points across the dictionary's text. Given the dominance of print resources and traditional cataloguing, such statements were inevitable and to be expected at this time; but within a couple of years this was changing, not least as researchers drew attention to previously unknown aspects of a life gleaned from new online sources. In response, $O D N B$ editors began a project in which articles were combed for these (and similar) phrases, and new record searches were undertaken, resulting so far in details of more than 2000 previously unknown births, marriages and deaths being added throughout the dictionary.

This work has been particularly rewarding in supplementing the lives of nineteenth and twentieth-century women, whose biographies are on occasions at risk of being obscured by multiple name changes, leading some to disappear from the historical record. Alternatively, there are instances where women have given false information about their age, often for professional reasons, which subsequently meant editors were led to the wrong register. One such case is the journalist and political activist Eleanor Vynne, who, as she became established as a writer in the 1890s, reduced her age in the census. As a result, in 2004 the $O D N B$ 's best estimate was that she had been born in '1870?', the daughter of Charles Vynne, a chemical manufacturer, with family ties in Norfolk. Alerted to the falsification, wider searches of newly available online resources identified Vynne as having been born 13 years earlier, on 31 October 1857, together with details of her place of birth (Kennington, Surrey), her immediate family, and a full account of her father, Charles, who, then an accountant, only later became manager of a fertiliser manufacturer following the family's move to north-west England. 
As well as improving existing biographies, digitised records allow editors to gather sufficient information to add to the dictionary people, perhaps notable for a well-documented event or once popular creative work, whose personal biography would previously have been too shadowy to justify an article. A century ago Henrietta Marshall's rousing history of Britain, Our Island Story (1905), was familiar to schoolchildren nationwide. ${ }^{9}$ Far less was known about its author; indeed, writing as H. E. Marshall, she obscured even her gender, to the extent that a centenary reissue of this, her most famous work, could not provide Marshall with firm birth or death dates and declared that 'little was known' of her life. Online searches of Scottish genealogical records, however, identified Marshall as the daughter of a Bo'ness manufacturer, while digitised regional newspapers provided an obituary report and enough material to trace a death certificate and probate, and with it details of her later residence in Hampstead, north London. The outcome was Marshall's inclusion in the ODNB with the first detailed account of her life in a recent selection of biographies relating to the history of children and childhood.

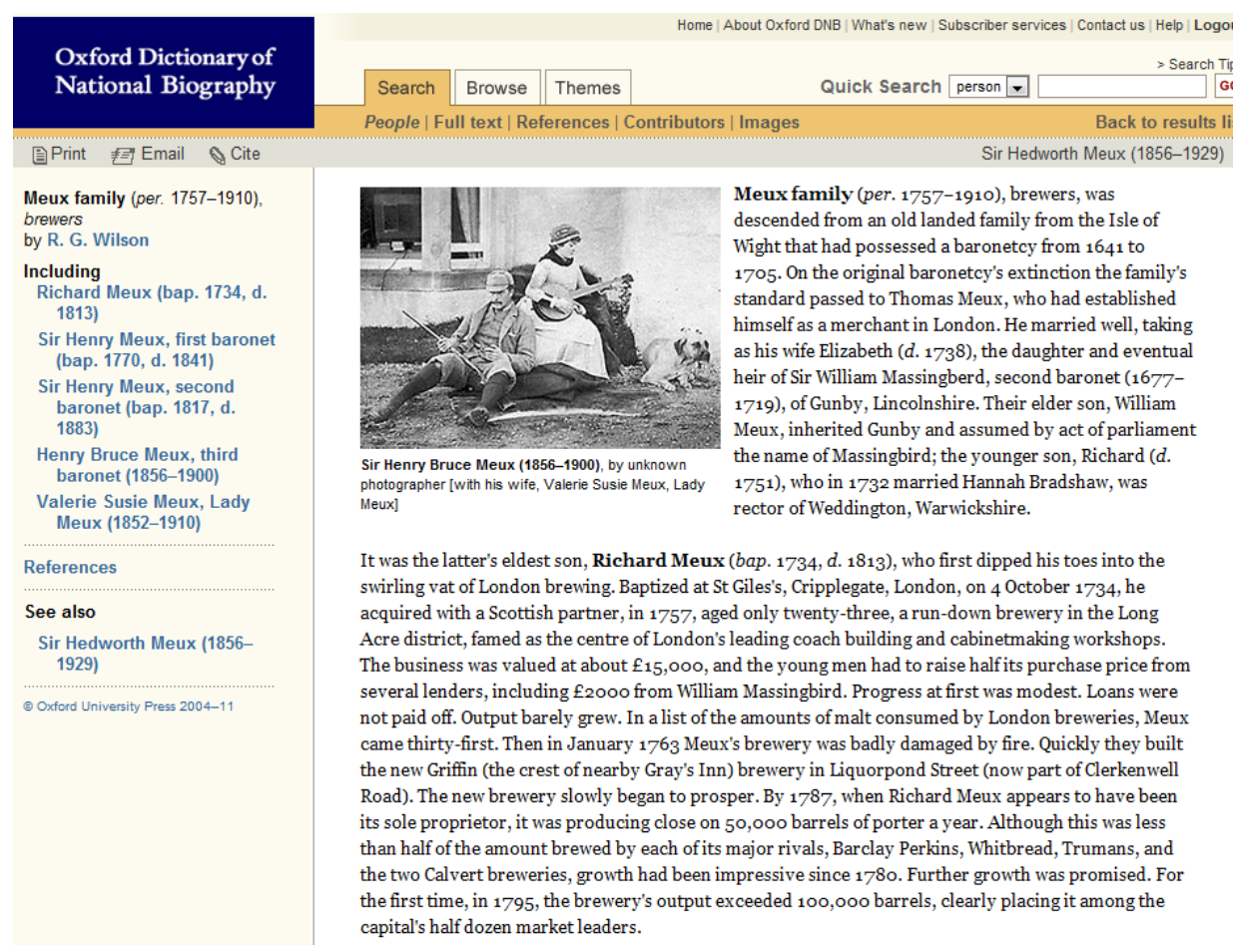

\section{Sir Henry and Lady Meux, subjects in an entry for the Meux brewing family (act. 1757-1910), published in 2007}

9 H. E. Marshall, with pictures by A. S. Forrest, Our Island Story: A Child's History of England (Edinburgh:

T. C. \& E. C. Jack, 1905). 
Similar investigative work is being done worldwide by thousands of researchers, many of whom, with remarkable generosity, make their findings available to us. One example of collaboration concerns the hitherto fabricated life of Valerie, Lady Meux. Twice painted by James Whistler, Valerie married into the Meux brewing family, which made her one of the wealthiest women in Edwardian England, able to devote her widowhood to collecting Egyptian antiquities (now in the British Museum), training the 1901 Derby winner, and giving $£ 20000$ for the purchase of guns for the defence of Ladysmith. To readers of Debretts this would have been 'just so' for there Lady Meux is listed, with reference to her marriage certificate, as 'Valerie, daughter of Charles Langton, gentleman', born in 1856. But thanks to research by family historians in New Zealand (to which, after her marriage, she sent many of her relatives), Lady Meux was identified as Susie Langton, born in 1852 (she changed her birth date to tally with her husband's), the second daughter of William Langton, a village butcher from rural Devon. Digging further, researchers discovered how Susie sought her fortune in London in the 1870s. Here she changed her name to 'Valerie Reece' and worked as an actress and hostess in the clubs of Westminster, where she met Henry Meux, heir to the family business. With access to online resources, this new information could be verified prior to her biography being added to the dictionary, being an unlikely and unexpected member of our series on regional brewers. To Susie Langton or Valerie Reece or Lady Meux, the discovery of her true past may not have been welcome, but for $O D N B$ editors it becomes a key part of her story, a fascinating case study of late-Victorian social mobility, and the first opportunity to identify accurately the sitter of Whistler's portraits.

The contribution of readers to improving and supplementing the dictionary's content is, if anything, even more pronounced for pre-nineteenth-century subjects whose lives, unrecorded in civil registration and other records, evade systematic reviews of near-comprehensive digital sources. For such subjects discoveries frequently originate with family historians who offer information from personal papers - that is, correspondence, diaries, portraits, even records of children in a family Bible - that have remained undisclosed and unknown until the $O D N B$ 's worldwide circulation online. This coming together of genealogical research and national biography can be remarkably productive in adding to what is known about selected early modern lives. Take, for example, the case of the Tudor churchman Robert Johnstone (d. 1558), to whose entry more than 30 years of family life, education and clerical career have now been added as a prelude to his period as a religious controversialist in the 1550s. Or Eliza Fay (1755/6-1816), the traveller best known for her posthumous Original Letters from India, whose $O D N B$ account has doubled in length owing to new research that minutely plots the troubled personal life that led her to travel repeatedly to India, and the business ventures she maintained there and in Britain as a single woman once separated from her wayward husband. 
As the Fay example shows, the addition of biographical detail can serve (while also 'humanising' an individual story) to re-emphasise the historical possibilities of national biography, offering, as here, a more rounded life (missing, incidentally, from a 2010 print reissue of her Letters), which provides greater context for a subject's better-known public actions. But even when there is less resonance between private and public lives, the supplementing of biographies with personal information remains a worthwhile activity. One of the great advantages of national biography online is that readerships extend well beyond those interested in the public actions of prominent figures. Consequently, new readers bring questions (and demands) that can relate equally to family, residence or places of residence and association. These, in turn, have the potential to prompt new connections and research among some of the hundreds of thousands of 'extras' in national biography - mothers, fathers, children, kinsmen, colleagues, teachers - who surround the principal subjects.

H. H. Pickersgill's widow, Jeannette Caroline Pickersgill [née Grover] (1814?-1885), born in Amsterdam, exhibited works at the Royal Academy between 1848 and 1863 and was 'well known in literary and scientific circles' (The Times, 27 March 1885). She was the first person to be legally cremated in the United Kingdom, following the trial of William Price, in 1884, when Sir James Fitzjames Stephen held that this mode of disposing of a body was not unlawful. She joined the Cremation Society in January 1885 , and died of broncho-pneumonia shortly afterwards, on 20 March 1885, at her home, 5 Cornwall Residences, Clarence Gate, Regent's Park, London, Her will contained instructions for cremation and, after an autopsy, this was carried out on 26 March 1885 at the crematorium established by the Cremation Society at St John's, Woking, Surrey. Her ashes were deposited at Kensal Green cemetery in 1887 .

The revised article for Henry Pickersgill in which his wife, Jeanette, now appears as a fully searchable co-subject of the main headword entry

Nor are such connections the preserve of readers alone. A welcome side effect of editors' reviews of dictionary content is the chance to highlight historical ties previously submerged within 68 million words of text. In 2008, for example, one set of new lives considered people responsible for modern forms of domestic and public hygiene and sanitation, including a leading advocate of the nascent practice of cremation. Research for the series identified the first person to be legally cremated in Britain, in 1885, as Jeannette Pickersgill. A search of the dictionary showed that Pickersgill was not a subject, but that there was a passing reference to Jeanette Caroline Grover (then presented without birth or death dates) as the wife of the painter Henry Hall Pickersgill (1812-61). To the original contributor of the Pickersgill entry, an art historian, and to the editor of the biography in 2004, Jeannette Grover was understandably regarded as the spouse of a more famous subject; but four years on, and seen from a previously 
unconsidered perspective, she emerges as a person of note, albeit one known by her married name. As a result, the entry has been recast to give Jeannette the status of a 'co-subject' within her husband's article in which she now appears with life dates and a note detailing her singular mark on the national record.

By her elevation to a 'co-subject', and hence to the dictionary's searchable index, Pickersgill becomes identifiable in her own right and by any of her name variants, not just the precise (maiden) name by which she originally appeared. This promotion of noteworthy people to the status of 'co-subjects' makes particular sense in an online environment. In 2004 the ODNB included 4809 individuals of this kind whose biographies, located within the text of another person, must in print be found through the relatively cumbersome procedure of cross-reference entries, often taking readers across several print volumes from the same edition (as with the 60-volume $O D N B$ ), or across different editions and several decades with the $A D B^{10}$ online; however, such figures are as easily found through name or category searching as a Shakespeare or a Churchill, and for this reason editors have paid close attention since 2005 to identifying figures who, briefly discussed in others' biographies, merit co-subject status. By dissolving the print hierarchy of principal and secondary subjects, the online edition offers readers a wider selection of 'interesting' people who may be worthy of further investigation regardless of whether they appear in the dictionary as 'full' or 'co-' subjects. What matters online therefore is less the lexicographical hierarchies and grammar of print than the discoverability and the research opportunities this might bring.

More broadly, and over time, such work also has the potential to address perennial questions of coverage, not just in the $O D N B$ but also in all national biographies. In compiling the 2004 edition, considerable effort was made to expand the number of female subjects, thus drawing on and reflecting twentiethcentury research interests. The outcome was a threefold increase throughout the dictionary, making women 10 per cent of subjects in all historical periods and nearly 30 per cent in the twentieth century. These proportions have been maintained dictionary-wide since 2005 and exceeded in the coverage of those who died in the opening years of the twenty-first century. Such proportions do prompt occasional complaint, sometimes accompanied by calls for attempts at parity of gender representation. In truth, the parameters in which national biographies exist - that is, to record historical 'noteworthiness' of lasting interest - ensure that such calls underplay the historically grounded inequality of opportunity, even among the very recently deceased. ${ }^{11}$ This is not, however,

10 James Walter notes the hindrances to research from the structures of print reference and provides an early comment on the possibilities of electronic publishing: 'Seven Questions about National Biography', pp. 28-9.

11 Questions of balance have also been raised with regard to newspaper obituaries; see, for example, 'Obituaries-Women's Final Frontier', Guardian [UK] (31 August 2010), reporting on criticism of New York 
a reason to do nothing. Combing recent research for new biographies is one approach that continues to lead to the inclusion of full subjects in the ODNB. ${ }^{12}$ Another is the elevation to co-subjects of those (of whom many, though not all, are women) who appeared in 2004 as parents, siblings, spouses or children, but whose own lasting achievements, often in non-public or non-professional roles, now see them fully incorporated in the national record. ${ }^{13}$

\section{Promoting and curating}

Over the past seven years the $O D N B$ has been shaped by concurrent projects that have extended, contextualised, refined and supplemented its online edition. To these one final activity might be added: that of promoting or 'curating' our collection. In doing so we return to the idea that, in digital format, national biographies serve as more than resources for quick person-focused reference, essential though this is. An earlier section of this chapter highlighted several formal ways (for example, group entries) in which editors encourage readers to treat national biography historically and, hence, as a starting point for teaching and research. But alongside these initiatives, which result in permanent additions to the dictionary, the online environment also makes possible similar work using less formal, temporary 'exhibitions' of selected content assembled around anniversaries or events and drawn from its collection of 58300 discrete items.

For editors and publishers, a key purpose of online 'outreach' is to extend the $O D N B$ 's take-up and use in schools, universities and via public libraries. Our intention is to make the <oxforddnb.com $>$ site interesting and topical as a means of promoting the dictionary, its content and online possibilities, both to existing readers and to those who would naturally fight shy of traditional biographical reference, print or digital. In doing so, editors have drawn on established models of online subscription - notably for academic journals - where rates of renewal and uptake are linked to regular additions of new material or 'value' to a title. As a result, and in addition to its three annual updates, the ODNB now

\footnotetext{
Times' limited inclusion of obituaries of women.

12 Recent additions to the $O D N B$ include the tenth-century queen Eadgyth, whose remains were discovered in Germany in 2010; silk-woman Alice Barnham (1523-1604), the principal subject of Lena Cowen Orlin's Locating Privacy in Tudor London (Oxford: Oxford University Press, 2007); the campaigning lawyer Gwyneth Bebb (1889-1921), whose achievements are only now being documented, as in Rosemary Auchmuty, 'Whatever Happened to Miss Bebb? Bebb v The Law Society and Women's Legal History', Legal Studies, 31, no. 2 (2011), pp. 199-230; and Violet Piercy (b. 1889?), the first modern woman to run a timed marathon (in 1936), whose life was researched from scratch to coincide with the 2012 Olympics.

13 Examples include the artist Mary Maria Fielding (1804-95), who collaborated with her husband, the botanist Henry Borron Fielding, and whose work is now discussed as part of Henry's entry; and Evan James (1809-78), lyricist of the Welsh national song, 'Land of My Fathers', the music for which was written by his son, James James, in whose entry Evan now appears.
} 
seeks to promote itself as an online 'service' providing topical interpretations of its content in daily, weekly or monthly instalments. The common thread is an attempt to entertain, educate and highlight new ways of looking at and using the dictionary.

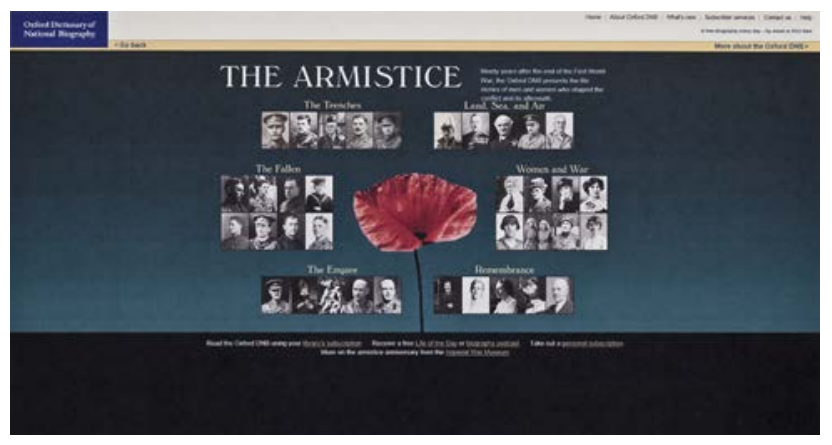

\section{The Armistice gallery, with links to 37 biographies, including that of the Unknown Warrior}

The development of this notion of an online service has been gradual and experimental. In areas such as its topical 'Life of the Day', the ODNB followed existing templates set up by the $A N B$ and since adopted (albeit without the facility for email distribution) by the $A D B$ online. Elsewhere new kinds of material, unique to the $O D N B$, have come about as needs and opportunities are identified. The dual role of updates in extending and drawing attention to existing content has, for example, given rise to accompanying 'feature essays', which place new and current subjects in historical perspective and offer routes into the main dictionary text. Written by editors and subject specialists, features of this kind include thematic surveys, from Roman Britain to concepts of heroism, as well as biographically focused studies of established historical topics, such as industrialisation, suffrage reform or life on the Home Front. ${ }^{14}$ On occasion, updates or significant anniversaries also lend themselves to visual presentations of content. The ninetieth anniversary of the Armistice, marked by the inclusion of 30 new wartime lives, was also commemorated with an interactive gallery combining familiar and less well-known aspects of the dictionary's 1914-18 coverage, including women and war, war and empire, and remembrance.

14 See, for example, Peter Salway, 'The Rise and Fall of Roman Britain' (2006), ODNB online, <www. oxforddnb.com/public/themes/92/92733.html>; Philip Carter, 'Courage and Popular Heroism in the Oxford DNB, c. 1850-2000' (2010), ODNB online, <www.oxforddnb.com/public/themes/101/101154.html>; and Paul Addison, 'Life on the Home Front, 1939-45' (2006), ODNB online, <www.oxforddnb.com/public/ themes/92/92741.html> 


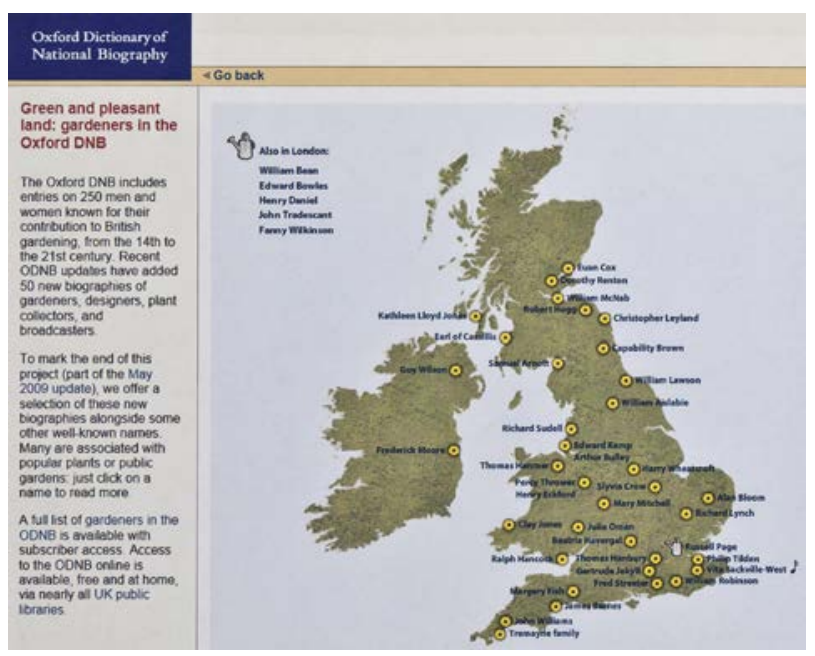

\section{Gardeners of the British Isles}

As the $O D N B^{\prime}$ s public profile grows, so it becomes easier to establish partnerships with other national institutions. Thus, the Armistice gallery was shared with the Imperial War Museum, London, while a number of joint events have been held with Tate Britain, the National Portrait Gallery, the BBC and the UK Parliament in which $O D N B$ biographies, of artists, sitters or other featured historical figures, are made publicly available on respective sites to offer 'further reading'. The result is, in effect, a parallel exhibition 'curated' by editors in which dictionary content is reconfigured and made accessible, akin to the $A D B^{\prime}$ s sharing of major lives in Australian democracy with the recently opened Museum of Australian Democracy at Old Parliament House, Canberra. ${ }^{15}$ The growing importance of the public library sector has similarly resulted in tie-ins with individual authorities in which bespoke web pages introduce library members to aspects of their local history while promoting the $O D N B$ 's free online availability. Identifying the dictionary as a resource for regional as well as national history has also led to the creation of a series of 'biographical maps', highlighting individuals and professional groups (for example, prominent regional manufacturers or, as here, gardeners and horticulturists) with particularly strong attachments to place.

Invariably such material is of greatest appeal to those with an existing interest in the past, be they museum and gallery goers or library and archive visitors studying local history. But an additional form of online publicity aims to push the dictionary's appeal well beyond the traditional scope of print publishing by appropriating popular images that lend themselves well to digital curation. Released in 2007 to mark the album's fortieth anniversary, the dictionary's

15 Darryl Bennet, 'NCB Collaborates with Museum of Australian Democracy', Biography Footnotes, no. 2 (March-April 2009). 
adaptation of the Beatles' 'Sgt Pepper' cover offers an unlikely combination of biographical reference, pop art and flower power. The result is an interactive graphic that introduces new readers not only to the $O D N B^{\prime}$ s entries on John Lennon and George Harrison, but also to other national figures featured in Peter Blake's artwork, from Lewis Carroll to Oscar Wilde. Still one of the most popular online features released by the $O D N B$, the 'Sgt Pepper' graphic was also noteworthy for including links to open-access $A N B$ content (Edgar Allan Poe to Marilyn Monroe), and followed a similar partnership with the $A D B$ online to highlight some of the two countries' greatest cricketers ahead of an Ashes series.

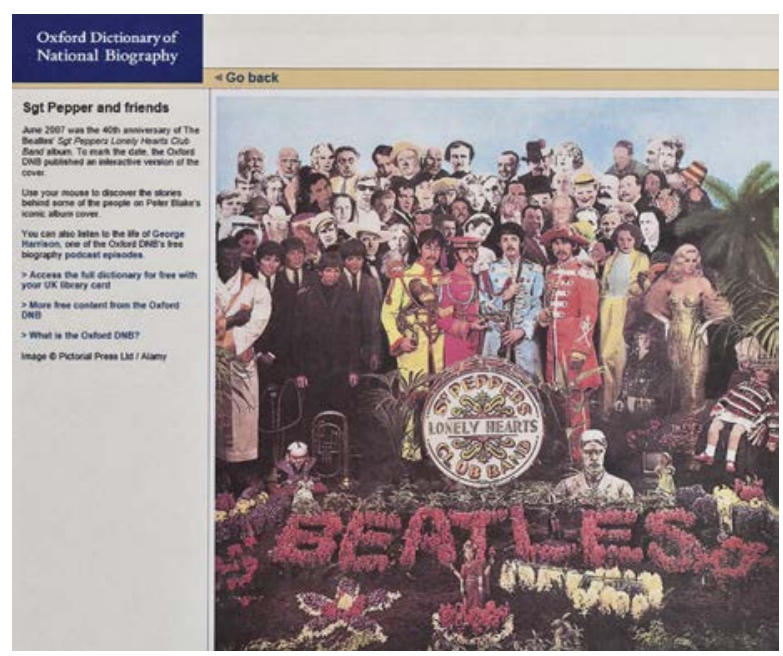

Sgt Pepper, with open-web links to $O D N B$ and $A N B$ biographies

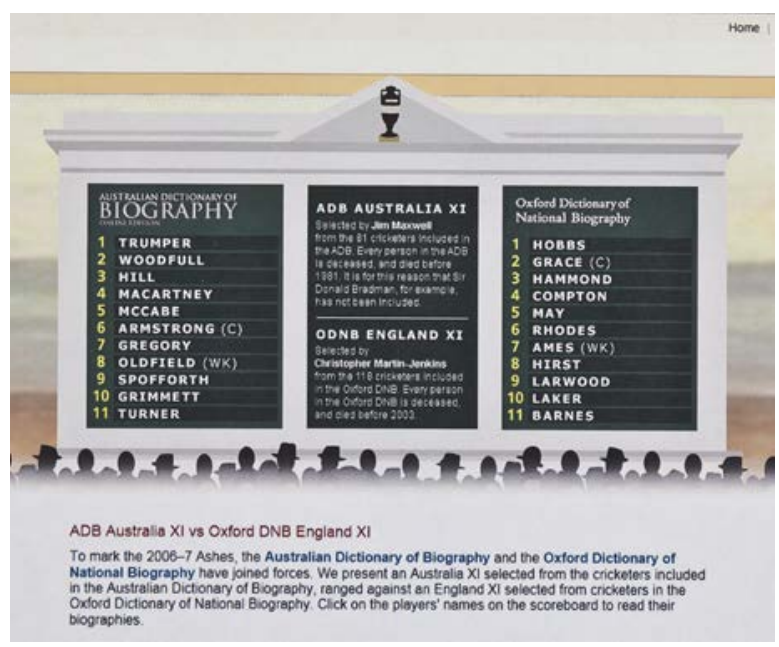

Two 'historical Ashes' teams selected from the $A D B$ and $O D N B$ by the commentators Jim Maxwell and Christopher Martin-Jenkins 
Online curation has also become easier and more effective thanks to the growth of social networking media. This, coupled with the concept of the $O D N B$ as a malleable, interpretable collection, creates new opportunities for traditional 'biographical reference' to be recast as 'life stories' marking popular anniversaries or offering historical perspectives on current events. The size of the audience willing to receive excerpted biographical content via social media like iTunes, Twitter and Facebook (in which the $O D N B$ routinely participates) is large and growing. In 2012 annual downloads of the dictionary's twice-monthly 'biography podcast', for example, reached about 650000 people, while the fluidity of social media users allows for the re-promotion of popular features, such as the Armistice, Ashes or Sgt Pepper, on subsequent, related anniversaries.

\section{Responses and future opportunities}

Since 2005 a number of initiatives - editorial, conservational and promotionalhave been set in train. But what have people made of this activity? For all its obvious importance, this is a far from easy question to answer given the difficulties of determining 'success' in an online environment in which comparisons of like with like are seldom as straightforward as those for print publishing. In short, when is a 'large number' of hits 'large enough'; when is a session time adequate; or when is a visit sufficiently imaginative given the range of searches and connections now possible? In view of these problems, it is perhaps more constructive to consider broader trends of use. Here, eight years on, visits to the dictionary and its public features continue to increase, as does UK public library use, which has experienced a marked rise following the introduction of some of the regular promotional items described above.

This is important not just because curation and promotion take editorial time but because increasing usage, together with comments from contributors and readers, suggests that these new, and sometimes populist, forms of online activity are not adversely affecting the $O D N B$ 's scholarly reputation. Different kinds of readers, it appears, are able to take up or ignore the various means, popular or scholarly, by which aspects of content are brought together and promoted. Moreover, it is important to the project that the innovations since 2005-namely, new biographies, themes and public engagement-remain the work of the dictionary's academic editors, who have decades invested in the $O D N B$, as well as academic profiles of their own. Consequently, nothing is done to risk compromising standing or reputation, with online outreach a mere 'shop window' on to biographical content that remains inviolable.

There have been questions regarding the implications of being online for the dictionary's wider reputation. Soon after publication came a concern that, 
in its new form, a classic work like the $O D N B$ would be too readily open to reinterpretation and revision. Surely, it was argued, a reference work should be 'fixed' not 'organic', with changes and revisions threatening the dictionary's historical standing as the final word on a life. These concerns aside, it is our impression that a growing, improving and engaging digital edition is considered an asset by the majority of readers. Most expect some omissions, inconsistencies and errors (inevitably easier to spot online) and are satisfied that these, and new additions to knowledge, can be frequently and systematically addressed in an academically moderated program that far exceeds what would be possible in print. Through these exchanges, Oxford editors are also building up a network of scholars who regularly submit information. The result is a 'second tier' of contributors, whom the $O D N B$ has always prized highly as its potential 'ambassadors', who now also see their (credited) research findings woven into articles across the dictionary. Thus, by regularly improving and refining the content, we sense most readers appreciate that what they find is, broadly speaking, 'as good as it can be' at the time of access, rather than (as it remains in print) a fine but increasingly outmoded snapshot of scholarship at the end of the twentieth century.

The opportunities (as well as the demands) to 'add value' mean that, six years on, a number of projects continue so as to improve the dictionary's content, retrieval and presentation online. In 2013 such work, often 'behind the scenes', includes tidying and extending the metadata to make searches more accurate, consistent and complete; the retrospective addition of images to biographies without a portrait in 2004; better integration of biographies with 'thematic reference' (lists and groups) so that searches for people also identify the public offices held or the networks to which they belonged; and adding links to accredited external sites by which readers may further pursue their research.

This inclusion of links out from the $O D N B$ continues work started before 2004 at which time connections were in place to the British National Portrait Gallery and Register of Archives, and (where applicable) to the ANB online. In each case the link provides a stable, reciprocal link with a person's record in the respective repository. Behind such work is an appreciation that the $O D N B$ online could not, and should not, be a 'one-stop/catch-all' site, but rather a locus for high-quality biographical information that also serves as a way station to equivalent resources in which portraits, archives or alternative biographies are curated to similarly high standards. Since 2005 this work of mediated connections has been extended to include secondary literature (the Royal Historical Society bibliographies) and additional OUP titles-notably, the eighteenth-century correspondence networks of the Voltaire Foundation's 'Electronic Enlightenment', the new Oxford English Dictionary online (launched in 2010), which includes references to thousands of $O D N B$ subjects in its 
quotation evidence, and from 2012 Oxford's Scholarly Editions online, which enables readers to click between an author's biography and his or her texts as discussed or quoted from in the dictionary entry. It is hoped that future links will also bring together shared lives in other national biographies, including the Dictionary of Irish Biography and the $A D B$.

Possibilities for greater reciprocity between the $O D N B$ and its fellow biographical dictionaries may also have implications for future forms of online use. It is common for those involved with national biography to speak of linking dictionaries together, allowing readers to compare the respective treatments of individuals who played a part in multiple national stories. ${ }^{16}$ On certain occasions this works extremely well, as with the recent inclusion of Victoria Woodhull (1838-1927) in the Oxford Dictionary. The political life of Woodhull, the first woman to stand for the US presidency, is covered in detail by her $A N B$ entry though little is said there about her equally colourful life in England, where she lived for 50 years, and which is now described for the first time by the $O D N B \cdot{ }^{17}$ Linking resources with distinctive remits can allow readers to construct a more nuanced biography built upon several specialist sources. Readers of political lives in the $O D N B$, for example, have things to gain from the History of Parliament (HoP) online, with its more detailed coverage of parliamentary performance; likewise readers of HoP can turn profitably to the $O D N B$, with its more rounded studies, which take in an individual's private and professional lives beyond Westminster. In general, however, the $O D N B$ 's experience suggests that relatively few scholars and students are, as yet, embracing even stand-alone national biographies as comparative resources. So it remains to be seen, and open to question, whether they can be encouraged to do so between national biographies in an exercise that will remain primarily historiographical, and where research findings may be limited given the brevity of coverage for most subjects in this format.

Perhaps the research opportunities for interconnected national biography could take different forms. Thus, one alternative is to interest scholars in the potential of collective biography for studying specific social-historical topics in which the $O D N B$ and $A D B$ (and now Obituaries Australia) are rich in detail and, online, well placed to deliver developments in family sizes, name forms, ages of marriage, lifespans, causes of death, religious affiliations, war records, cultural ties, forms of education, social and geographical mobility within a country, to name a few. While alert to the particularities of individual national repositories

16 The possibilities for, and limitations of, interconnected national biographies are considered in Lawrence Goldman, 'Virtual Lives: History and Biography in an Electronic Age', Australian Book Review (June 2007), pp. 37-44.

17 Lawrence Goldman, 'Victoria Clafin Woodhull (1838-1927), Women's Rights Campaigner and First Female US Presidential Candidate', ODNB online, <www.oxforddnb.com/view/article/98231> In England, Woodhull reinvented herself as a country landowner and campaigner for Anglo-American friendship. Cremated and commemorated in Tewkesbury Abbey, Gloucestershire, her ashes were scattered, fittingly, in the mid Atlantic. 
(and to the selective nature of these data sets), it may also be possible to compare social trends across different works or, in the case of mobility, to survey national biographies for what they might tell us about patterns of international travel and migration by people organised more nebulously by family, professional groups, places of origin or age. As the record of a former imperial power, the $O D N B$, in association with other national biographies, has potentially much to offer here, facilitating the development of recent interest in micro-histories of empire written from the perspective of life stories. ${ }^{18}$

As the $A D B$ enters its second half-century, we have an opportunity both to look back, on print volumes published, and to look forward to extended online coverage, enhanced interpretative reference and new research initiatives, such as Obituaries Australia. In terms of its chronology, the brief history of the $O D N B$ is only one-tenth that of the $A D B$. By reflecting on aspects of this short history, this chapter has highlighted some of the opportunities the ODNB's now predominant online edition offers its editors and readers, and may also create for those of other national biographies. Though at times demanding and labour intensive, the Oxford experience suggests that an online environment brings considerable benefits to the wider project in several ways.

First, online activity provides editors with greater freedom to decide what is published and how editorial work is organised. Freed from the constraints of volumes and alphabetical sequences, it is possible to commission, review and edit thematically, allowing for more effective use by specialist authors and reviewers in assessing and reviewing future content. Second, an online presence shifts perceptions of national biography and, with it, the potential to appeal to existing and new readerships. Transformed from a static 'publication' to a flexible, interpretable 'national collection', the $O D N B$ is gradually gaining a presence in public life that is no longer restricted to volume launches or even (as the idea of a regular online 'service' develops) to formal annual updates of new biographical content.

Third, online activity brings unexpected benefits, scholarly and curatorial, throughout the project: extending biographical coverage can lead to better appreciation and visibility of existing content; adding lists and groups identifies omissions even when the editorial collective memory is strong; curation, as well as broadening readership, generates new information; while first-time contributors extend the dictionary's advocates among scholars and students.

18 For example, the two volumes edited by Desley Deacon, Penny Russell and Angela Woollacott (eds): Transnational Ties: Australian Lives in theWorld (Canberra: ANU E Press, 2008) and Transnational Lives: Biographies of Global Modernity, 1700 to the Present (Basingstoke, UK, and New York: Palgrave MacMillan, 2010). Also David Lambert and Alan Lester (eds), Colonial Lives across the British Empire. Imperial Careering in the Long Nineteenth Century (Cambridge: Cambridge University Press, 2009); and Elizabeth Buettner, Empire Families. Britons in Late Imperial India (Oxford University Press: Oxford, 2004). 
Fourth, online activity is popular and is being embraced even by seasoned readers of print reference in whom we might have expected greater reticence. Indeed, the $O D N B^{\prime}$ s short history suggests that future challenges lie less in convincing established scholars (who have moved quickly from print to online when publishing protocols and standards are maintained) than in shepherding younger users towards more considered online activity. ${ }^{19}$ For some scholars the attraction of online is evidently its opportunities for teaching and research although a further challenge remains how to encourage greater awareness of these research possibilities and methods in the move from singular biography to history through people.

Finally, to compile and publish national biography online is to be part of something innovative and rewarding. Accessible, quality reference works, in touch with new research through updates and refinements, are still rare and immensely valuable. This of course brings its own pressures. The rapid growth of online sources and research means that keeping in step with what others are doing is now essential if digital biographies are not to become dated resources. This is not and will not be easy, but being online makes it possible in ways inconceivable in print.

Dr Philip Carter is Publication Editor at the Oxford Dictionary of National Biography.

19 Here the situation may be changing. Recent research suggests that a new generation of students is learning to differentiate online between 'starting-point' resources such as Wikipedia and accredited, peerreviewed resources such as the $O D N B$ and $A D B$, to which they move on, especially when links are provided in open-web encyclopedias. See Alison J. Head and Michael B. Eisenberg, ‘How Today's College Students use Wikipedia', First Monday, 15, no. 3 (1 March 2010), <www.firstmonday.org/htbin/cgiwrap/bin/ojs/index. $\mathrm{php/fm/article/view/2830/2476>}$ 